\title{
Indicadores IBGE
}

Pesquisa Nacional por Amostra de Domicílios Contínua

\author{
Trimestre Móvel \\ JAN. - MAR. 2020
}

Publicado em 30/04/2020 às 9 horas 
Presidente da República

Jair M essias Bolson aro

Ministro da Economia

Paulo Rob erto Nunes Gued es

Secretário E special de Fazenda

Waldery Rod rigues Junior

\section{INSTITU TO BRASILE IRO DE GE OGRAFIA E \\ E ST ATÍSTICA - IBGE}

Presidente

Su sana Cord eiro G uerra

Diretor-Ex ecutivo

Fernand o José de Araújo Abrantes

\section{ORG ÃOS ESPECIFICOS SINGUIARES}

Diretoria de Pesquisas

E duard o Luiz G. Rios Neto

Diretoria de $\mathrm{G}$ eociências

João Bosco de Azev ed 0

Diretoria de Informática

David Wu Tai

Centro de Documentação e Disseminação de Informações $\mathbf{M}$ arise $\mathbf{M}$ a ria Ferreira

Escola Nacional de Ciências E statisticas

Maysa Sacramento de $M$ agalhães

UNIDADE RESPONSÁVEL

Diretoria de Pesquisas

Coor denação de Trabalho e Rendimento

Maria Lucia França Pontes Vieira

Equipe de Análise de Resultados

Adriana Araujo Beringuy

Alessandra Scalioni Brito

Cimar Azeredo Pereira

Lino E duardo Rodrigues Pereira

Ricardo da Silva L opes

\section{Ind icad ores IBGE}

Plano de divul gação:

Trab alho e rendimento

Pesquisa mensal de emprego*

Pesquisa nacional por am ostra de domicilios continua Agropecuária

Estatistica da produção agricola **

Estatistica da produção pecuária **

Ind úst ria

Pesquisa industrial mensal: emprego e salário ***

Pesquisa industrial mensal: produção física Brasil

Pesquisa industrial mensal: produção fisica regional

Comércio

Pesquisa mensal de comércio

Serviços

Pesquisa mensal de serviços

Ind ices, p recos e cust os

Indice de preços ao produtor - indústrias extrativas e de transformação

Sistema nacional de indices de preços ao consumidor:

IPCA-E

Sistema nacional de indices de preços ao consumidor:

INPC - IPCA

Sistema nacional de pesquisa de custos e indices da construção civil

Contas nacionais trimestrais

Contas nacionais trimestrais: indicadores de volume $e$

valores correntes

* O último fasciculo divul gado corresponde a fevereiro de 2016.

** Continuação de: Estatistica da produção agropecuária, a partir de janeiro de 2006. A produção agricola é composta do L evantamento Sistemático da Produção Agricola. A produção pecuária é composta da Pesquisa Trim estral do Abate de Anim ais, da Pesquisa Trimestral do L eite, da Pesquisa Trimestral do Couro e da Produção de Ovos de $\mathrm{G}$ alinha.

***: $O$ último fasciculo divulgado corresponde a dezem bro de 2015

Iriciado em 19\$2, com a divulgação de indicadores sobre trabalho e rendimento, indistria e preços, o periódico Indicad ores IBGE passou a incorporar, no decorrer das décadas seguintes, informações sobre agropecuária, contas nacionais trimestrais e serviços, visando contemplar as variadas demandas por estatisticas conjunturais para o Pais. Outros temas poderão ser abarcados futuramente, de acordo com as necessidades de informação identificadas. $O$ periódico é subdividido em fasciculos por temas especificos, que incluem tabelas de resultados, comentários e notas metodológicas. As informações apresentadas estão disponiveis em diferentes niveis geográficos: nacional, regional e metropolitano, variando por fasciculo 


\title{
Pesquisa Nacional por Amostra de Domicílios Contínua
}

\author{
Mercado de Trabalho Conjuntural \\ Divulgação Mensal - março de 2020
}

Data de divulgação: 30 de abril de 2020

Abrangência Geográfica: Brasil

Construção dos Indicadores: trimestre móvel

Período: janeiro a março de 2020

Principais destaques no trimestre móvel de janeiro a março de 2020 As comparações foram feitas em relação ao trimestre móvel de:

Outubro a dezembro de 2019

Onde $\mathbf{8 0 \%}$ dos domicílios selecionados são os mesmos, mas as informações nestes domicílios foram coletadas novamente, portanto, não existe repetição de informação entre os trimestres analisados.
Janeiro a março de 2019

Onde $\mathbf{2 0 \%}$ dos domicílios selecionados são os mesmos, mas as informações nestes domicílios foram coletadas novamente, portanto, não existe repetição de informação entre os trimestres analisados.

\section{DESOCUPAÇÃO}

- A taxa de desocupação foi estimada em 12,2\% no trimestre móvel referente aos meses de janeiro a março de 2020, registrando variação de 1,3 ponto percentual em relação ao trimestre de outubro a dezembro de 2019 (11,0\%). Na comparação com o mesmo trimestre móvel do ano anterior, janeiro a março de 2019, quando a taxa foi estimada em $12,7 \%$, o quadro foi de queda (-0,5 ponto percentual). 
Quadro 1 - Taxa de Desocupação - Brasil - 2012/2020

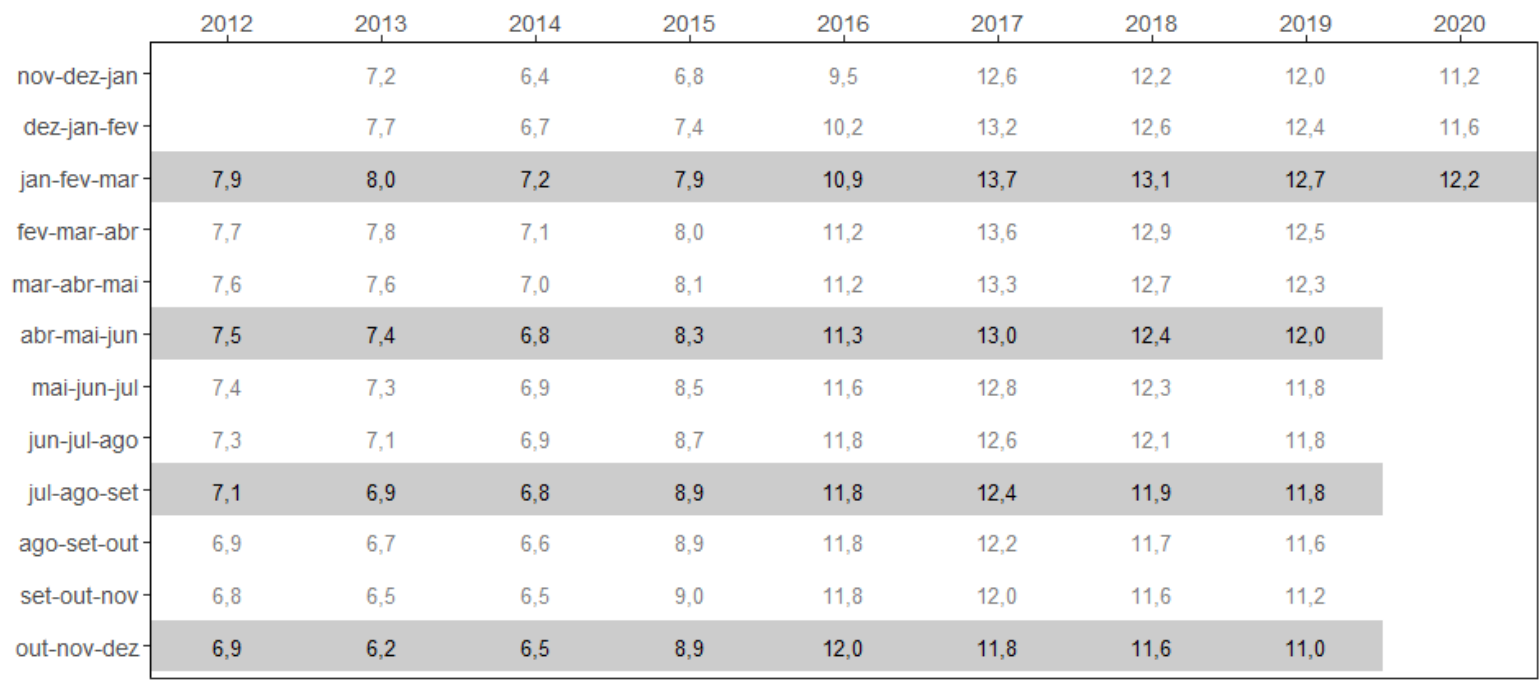

Fonte: IBGE, Pesquisa Nacional por Amostra de Domicilios Contínua

Nota: Somente os dados hachurados são comparáveis.

- No trimestre de janeiro a março de 2020, havia aproximadamente 12,9 milhões de pessoas desocupadas no Brasil. Este contingente apresentou variação de 10,5\%, ou seja, mais 1218 mil pessoas frente ao trimestre de outubro a dezembro de 2019, ocasião em que a desocupação foi estimada em 11,6 milhões de pessoas. No confronto com igual trimestre do ano anterior, quando havia 13,4 milhões de pessoas desocupadas, esta estimativa apresentou variação de $-4,0 \%$, significando uma redução de 537 mil pessoas desocupadas na força de trabalho.

\section{OCUPAÇÃO}

- O contingente de pessoas ocupadas foi estimado em aproximadamente 92,2 milhões no trimestre de janeiro a março de 2020 . Essa estimativa apresentou redução de $-2,5 \%$, ou seja, menos 2329 mil pessoas em relação ao trimestre anterior (outubro a dezembro de 2019). Em relação ao mesmo trimestre do ano anterior (janeiro a março de 2019) este indicador apresentou estabilidade.

- O nível da ocupação (indicador que mede o percentual de pessoas ocupadas na população em idade de trabalhar) foi estimado em $53,5 \%$ no trimestre de janeiro a março de 2020, apresentando uma redução de 1,6 pontos percentuais frente ao trimestre de outubro a dezembro de 2019 (55,1\%). Em relação a igual trimestre do ano anterior, este indicador apresentou variação negativa $(0,4$ ponto percentual), quando 0 nível da ocupação no Brasil foi de 53,9\%. 
Quadro 2 - Nível da Ocupação - Brasil - 2012/2020

\begin{tabular}{|c|c|c|c|c|c|c|c|c|c|}
\hline & 2012 & 2013 & 2014 & 2015 & 2016 & 2017 & 2018 & 2019 & 2020 \\
\hline nov-dez-jan - & & 56,8 & 57,1 & 56,7 & 55,5 & 53,7 & 54,2 & 54,2 & 54,8 \\
\hline dez-jan-fev- & & 56,5 & 57,0 & 56,4 & 55,1 & 53,4 & 53,9 & 53,9 & 54,5 \\
\hline jan-fev-mar- & 56,3 & 56,3 & 56,8 & 56,2 & 54,8 & 53,1 & 53,6 & 53,9 & 53,5 \\
\hline fev-mar-abr- & 56,7 & 56,5 & 56,8 & 56,3 & 54,6 & 53,2 & 53,6 & 54,2 & \\
\hline abr-mai-jun - & 57,1 & 56,9 & 56,9 & 56,2 & 54,6 & 53,7 & 53,7 & 54,6 & \\
\hline mai-jun-jul- & 57,0 & 57,0 & 56,8 & 56,1 & 54,4 & 53,9 & 53,9 & 54,7 & \\
\hline jun-jul-ago- & 57,1 & 57,0 & 56,7 & 56,0 & 54,2 & 54,0 & 54,1 & 54,7 & \\
\hline jul-ago-set & 57,2 & 57,1 & 56,8 & 56,0 & 54,0 & 54,1 & 54,4 & 54,8 & \\
\hline out-nov-dez- & 57,1 & 57,3 & 56,9 & 55,9 & 54,0 & 54,5 & 54,5 & 55,1 & \\
\hline
\end{tabular}

Fonte: IBGE, Pesquisa Nacional por Amostra de Domicilios Contínua Nota: Somente os dados hachurados são comparáveis.

\section{POPULAÇÃO NA FORÇA DE TRABALHO}

- O contingente na força de trabalho (pessoas ocupadas e desocupadas), no trimestre de janeiro a março de 2020, foi estimado em 105,1 milhões de pessoas. Observou-se que esta população apresentou uma redução de 1111 mil pessoas $(-1,0 \%)$, quando comparada com o trimestre de outubro a dezembro de 2019. Frente ao mesmo trimestre do ano anterior, houve estabilidade.

\section{TAXA DE PARTICIPAÇÃO DA FORÇA DE TRABALHO}

- A taxa de participação da força de trabalho (indicador que mede o percentual de pessoas da força de trabalho na população em idade de trabalhar) foi estimada em $61,0 \%$ no trimestre de janeiro a março de 2020 , uma redução de 0,9 ponto percentual frente ao trimestre de outubro a dezembro de 2019 (61,9\%). Em relação a igual trimestre do ano anterior (61,7\%), o cenário foi de contração de 0,8 ponto percentual.

\section{POSIÇÃO NA OCUPAÇÃO E CATEGORIA DO EMPREGO}

- $\quad$ O contingente de empregados no setor privado com carteira de trabalho assinada (exclusive trabalhadores domésticos), estimado em 33,1 milhões de pessoas, apresentou uma redução de 572 mil pessoas $(-1,7 \%)$ frente ao trimestre anterior (outubro a dezembro de 2019). No confronto com o trimestre de janeiro a março de 2019, houve estabilidade.

- $\quad$ No período de janeiro a março de 2020, a categoria dos empregados no setor privado sem carteira de trabalho assinada (11,0 milhões de pessoas) apresentou uma redução de 832 mil pessoas. Em relação ao mesmo trimestre do ano anterior, foi registrado estabilidade.

- Na categoria dos trabalhadores por conta própria, formada por 24,2 milhões de pessoas, foi registrada redução de $(-1,6 \%$ na comparação com o trimestre anterior (outubro a dezembro de 2019), significando uma subtração de 398 mil pessoas neste 
contingente. Em relação ao mesmo período do ano anterior, o indicador, em oposição, apresentou elevação (1,7\%), representando um adicional estimado de 409 mil pessoas.

- No período de janeiro a março de 2020, a categoria dos empregadores (4,4 milhões de pessoas) apresentou estabilidade em relação ao trimestre anterior. Em relação ao mesmo trimestre do ano anterior, foi registrado, também, estabilidade.

- A categoria dos trabalhadores domésticos, estimada em 6,0 milhões de pessoas, apresentou redução de 6,1\% no confronto com o trimestre de outubro a dezembro de 2019. Frente ao trimestre de janeiro a março de 2019, o cenário foi de estabilidade.

- O grupo dos empregados no setor público (inclusive servidores estatutários e militares), estimado em 11,7 milhões de pessoas, apresentou estabilidade frente ao trimestre anterior. Ao se comparar com o mesmo trimestre do ano anterior, houve elevação de $2,6 \%$, representando um adicional estimado de 290 mil pessoas.

\section{GRUPAMENTOS DE ATIVIDADE}

- A análise do contingente de ocupados, segundo os grupamentos de atividade, do trimestre móvel de janeiro a março de 2020, em relação ao trimestre de outubro a dezembro de 2019, mostrou que não houve crescimento em qualquer grupamento. Houve redução nos seguintes grupamentos: Indústria $(2,6 \%$, ou menos 322 mil pessoas), Construção (6,5\%, ou menos 440 mil pessoas), Comércio, reparação de veículos automotores e motocicletas (3,5\%, ou menos 628 mil pessoas), Alojamento e alimentação (5,4\%, ou menos 308 mil pessoas), Outros serviços (4,1\%, ou menos 211 mil pessoas) e Serviços domésticos (5,9\%, ou menos 376 mil pessoas)

- Na comparação com o trimestre de janeiro a março de 2019 foi observado aumento no grupamento de Administração pública, defesa, seguridade social, educação, saúde humana e serviços sociais ( $3,4 \%$, ou mais 543 mil pessoas). Os demais grupamentos não apresentaram variação significativa. 
Classificaçäo Nacional de Atïidades Econômicas Domicitar 2.0

(agrupamentos para efeito de divulgacōo da PNAD Contínua)

\begin{tabular}{|c|c|c|}
\hline 1 & \multicolumn{2}{|c|}{ AGRICULTURA, PECUÁRIA, PRODUÇÃO FLORESTAL, PESCA E AQUICULTURA } \\
\hline \multirow{4}{*}{2} & \multirow{4}{*}{ INDÚSTRIA GERAL } & INDÚSTRIAS EXTRATIVAS \\
\hline & & INDÚSTRIAS DE TRANSFORMAÇÄO \\
\hline & & ELETRICIDADE E GÁS \\
\hline & & ÁGUA, ESGOTO, ATIVIDADES DE GESTÄO DE RESÍDUOS E DESCONTAMINAÇÃO \\
\hline \multirow{3}{*}{3} & \multirow{3}{*}{ CONSTRUÇÄO } & CONSTRUÇÄO E INCORPORAÇÄO DE EDIFÍCIOS \\
\hline & & OBRAS DE INFRA-ESTRUTURA \\
\hline & & SERVIÇOS ESPECIALIZADOS PARA CONSTRUÇÄO \\
\hline \multirow[t]{2}{*}{4} & \multirow{2}{*}{$\begin{array}{c}\text { COMÉRCIO, REPARAÇÃO DE } \\
\text { VEÍCULOS AUTOMOTORES E } \\
\text { MOTOCICLETAS }\end{array}$} & $\begin{array}{l}\text { COMÉRCIO EM GERAL (incluindo o comércio de veículos automotores e motocicletas) e (excluindo o } \\
\text { serviço de alimentaçâo, tais como: bares restaurante e lanchonete etc) }\end{array}$ \\
\hline & & REPARAÇÃO DE VEICCULOS AUTOMOTORES E MOTOCICLETAS \\
\hline \multirow{5}{*}{5} & \multirow{5}{*}{$\begin{array}{l}\text { TRANSPORTE, } \\
\text { ARMAZENAGEM E CORREIO }\end{array}$} & TRANSPORTE TERRESTRE \\
\hline & & TRANSPORTE AQUAVIÁRIO \\
\hline & & TRANSPORTE AÉREO \\
\hline & & ARMAZENAMENTO E ATIVIDADES AUXILIARES DOS TRANSPORTES \\
\hline & & CORREIO E OUTRAS ATIVIDADES DE ENTREGA \\
\hline 6 & ALOJAMENTO E ALIMENTAÇÄO & \\
\hline \multirow{5}{*}{7} & \multirow{5}{*}{\begin{tabular}{|c|} 
INFORMAÇÃO, \\
COMUNICAÇÃO E ATIVIDADES \\
FINANCEIRAS, IMOBILIÁRIAS, \\
PROFISSIONAISE \\
ADMINISTRATIVAS \\
\end{tabular}} & INFORMAÇÄO E COMUNICAÇÄO \\
\hline & & ATIVIDADES FINANCEIRAS, DE SEGUROS E SERVIÇOS RELACIONADOS \\
\hline & & ATIVIDADES IMOBILIÁRIAS \\
\hline & & ATIVIDADES PROFISSIONAIS, CIENTÍFICAS E TÉCNICAS \\
\hline & & ATIVIDADES ADMINISTRATIVAS E SERVIÇOS COMPLEMENTARES \\
\hline \multirow{3}{*}{8} & \multirow{3}{*}{$\begin{array}{l}\text { ADMINISTRACČ̃̃O PÚBLICA, } \\
\text { DEFESA, SEGURIDADE SOCIAL, } \\
\text { EDUCAÇÃO, SAÚDE HUMANA } \\
\end{array}$} & ADMINISTRAÇÄO PÚBLICA, DEFESA E SEGURIDADE SOCIAL \\
\hline & & EDUCAÇÄO (pública e privada) \\
\hline & & SAÚDE HUMANA (pública e privada) E SERVIÇOS SOCIAIS \\
\hline \multirow{5}{*}{9} & \multirow{5}{*}{ OUTROS SERVIÇOS } & ARTES, CULTURA, ESPORTE E RECREAÇÃO \\
\hline & & ATIVIDADES DE ORGANIZAÇÖES ASSOCIATIVAS \\
\hline & & $\begin{array}{l}\text { REPARAÇÃO E MANUTENÇẢO DE EQUIPAMENTOS DE INFORMATICA E COMUNICAÇÃO E DE OBJETOS } \\
\text { PESSOAIS E DOMÉSTICOS }\end{array}$ \\
\hline & & OUTRAS ATIVIDADES DE SERVIÇOS PESSOAIS \\
\hline & & ORGANISMOS INTERNACIONAIS E OUTRAS INSTITUIÇŐES EXTRATERRITORIAIS \\
\hline 10 & \multicolumn{2}{|l|}{ SERVIÇOS DOMÉSTICOS } \\
\hline 11 & \multicolumn{2}{|l|}{ ATIVIDADES MAL DEFINIDAS } \\
\hline
\end{tabular}

\section{SUBUTILIZAÇÃO DA FORÇA DE TRABALHO}

- A taxa composta de subutilização da força de trabalho (Percentual de pessoas desocupadas, subocupadas por insuficiência de horas trabalhadas e na força de trabalho potencial em relação a Força de trabalho ampliada) foi estimada em $24,4 \%$ no trimestre móvel referente aos meses de janeiro a março de 2020, registrando variação de 1,4 ponto percentual em relação ao trimestre de outubro a dezembro de 2019 $(23,0 \%)$. Na comparação com o mesmo trimestre móvel do ano anterior, janeiro a março de 2019, quando a taxa foi estimada em $25,0 \%$, o quadro foi de queda $(-0,6$ ponto percentual).

- No trimestre de janeiro a março de 2020, havia aproximadamente 27,6 milhões de pessoas subutilizadas no Brasil. Este contingente apresentou variação de $5,6 \%$, ou seja, mais 1462 mil pessoas, frente ao trimestre de outubro a dezembro de 2019, ocasião em que a subutilização foi estimada em 26,2 milhões de pessoas. No confronto com igual trimestre do ano anterior, quando havia 28,3 milhões de pessoas subutilizadas, esta estimativa apresentou variação de $-2,5 \%$, significando uma redução de 704 mil pessoas subutilizadas. 


\section{SUBOCUPAÇÃO}

- O contingente de pessoas subocupadas por insuficiência de horas trabalhadas foi estimado em aproximadamente 6,5 milhões no trimestre de janeiro a março de 2020. Essa estimativa apresentou redução em relação ao trimestre anterior (outubro a dezembro de 2019) de $-4,8 \%$, ou seja, uma redução de 325 mil pessoas. Em relação ao mesmo trimestre do ano anterior (janeiro a março de 2019) este indicador apresentou, também, variação negativa $(-4,4 \%)$, quando havia no Brasil 6,8 milhões de pessoas subocupadas.

\section{POPULAÇÃO FORA DA FORÇA DE TRABALHO}

- O contingente fora da força de trabalho, no trimestre de janeiro a março de 2020, foi estimado em 67,3 milhões de pessoas. Observou-se que esta população apresentou um incremento de 1851 mil pessoas (2,8\%) quando comparada com o trimestre de outubro a dezembro de 2019. Frente ao mesmo trimestre do ano anterior, houve expansão de 3,1\% (acréscimo de 2,0 milhões de pessoas).

\section{POPULAÇÃO NA FORÇA DE TRABALHO POTENCIAL}

- O contingente na força de trabalho potencial ${ }^{1}$, no trimestre de janeiro a março de 2020, foi estimado em 8,3 milhões de pessoas. Observou-se que esta população apresentou um incremento de 568 mil pessoas (7,3\%) quando comparada com o trimestre de outubro a dezembro de 2019. Frente ao mesmo trimestre do ano anterior houve estabilidade.

\section{DESALENTO}

- O contingente de pessoas desalentadas ${ }^{2}$ foi estimado em aproximadamente 4,8 milhões no trimestre de janeiro a março de 2020. Essa estimativa apresentou estabilidade em relação ao trimestre anterior (outubro a dezembro de 2019). Em

\footnotetext{
${ }^{1}$ Composta por pessoas de 14 anos ou mais de idade, que na semana de referência não estavam ocupadas nem desocupadas, mas possuíam um potencial de se transformarem em força de trabalho. Este contingente está dividido em dois grupos: $O$ daqueles que realizaram busca efetiva por trabalho no período de 30 dias, mas não se encontravam disponíveis para trabalhar na semana de referência em função dos seguintes motivos: 1 - Tinha que cuidar dos afazeres domésticos, do(s) filho(s) ou de outro(s) parente(s); 2 - Estava estudando (em curso de qualquer tipo ou por conta própria); 3 - Por problema de saúde ou gravidez; 4 - Por ser muito jovem ou muito idoso para trabalhar; e 5 - Por não querer trabalhar. Também, por aqueles que não haviam realizado busca efetiva por trabalho no período de 30 dias, mas gostariam de ter um trabalho e estavam disponíveis para trabalhar na semana de referência em função dos seguintes motivos: conseguiu proposta de trabalho para começar após a semana de referência; estava aguardando resposta de medida tomada para conseguir trabalho não conseguia trabalho adequado; não tinha experiência profissional ou qualificação; não conseguia trabalho por ser considerado muito jovem ou muito idoso; não havia trabalho na localidade; tinha que cuidar dos afazeres domésticos, do(s) filho(s) ou de outro(s) parente(s); estava estudando (em curso de qualquer tipo ou por conta própria); por problema de saúde ou gravidez.

${ }^{2}$ Composta pelo subgrupo de pessoas da força de trabalho potencial que não haviam realizado busca efetiva por trabalho por considerar que: não conseguiriam trabalho adequado; não tinham experiência profissional ou qualificação; não conseguiam trabalho por serem considerados muito jovens ou muito idosos ou não havia trabalho na localidade. Todavia, gostariam de ter um trabalho e estavam disponíveis para trabalhar na semana de referência.
} 
relação ao mesmo trimestre do ano anterior (janeiro a março de 2019) este indicador apresentou, também, estabilidade.

- O Percentual de pessoas desalentadas em relação à população na força de trabalho ou desalentada foi estimada em $4,3 \%$ no trimestre móvel referente aos meses de janeiro a março de 2020, registrando variação de 0,2 ponto percentual em relação ao trimestre de outubro a dezembro de 2019 (4,2\%). Na comparação com o mesmo trimestre móvel do ano anterior, janeiro a março de 2019, quando a taxa foi estimada em $4,4 \%$, o quadro foi de estabilidade.

\section{RENDIMENTO MÉDIO REAL HABITUAL}

- O rendimento médio real habitualmente recebido em todos os trabalhos pelas pessoas ocupadas foi estimado em R\$ 2398 no trimestre de janeiro a março de 2020, registrando estabilidade frente ao trimestre de outubro a dezembro de 2019 e, também, em relação ao mesmo trimestre do ano anterior.

Quadro 3 - Rendimento médio mensal real, habitualmente recebido no mês de referência, de todos os trabalhos das pessoas ocupadas - Brasil - 2012/2020 - (R\$)

\begin{tabular}{|c|c|c|c|c|c|c|c|c|c|}
\hline & 2012 & 2013 & 2014 & 2015 & 2016 & 2017 & 20,18 & 2019 & 2020 \\
\hline nov-dez-jan- & & 2249 & 2314 & 2367 & 2288 & 2305 & 2336 & 2377 & 2378 \\
\hline dez-jan-fev- & & 2265 & 2336 & 2362 & 2274 & 2311 & 2346 & 2386 & 2379 \\
\hline jan-fev-mar- & 2224 & 2277 & 2360 & 2362 & 2292 & 2324 & 2346 & 2378 & 2398 \\
\hline fev-mar-abr- & 2236 & 2283 & 2360 & 2356 & 2274 & 2314 & 2355 & 2366 & \\
\hline abr-mai-jun- & 2233 & 2305 & 2347 & 2350 & 2258 & 2302 & 2353 & 2347 & \\
\hline mai-jun-jul- & 2244 & 2321 & 2343 & 2333 & 2261 & 2303 & 2345 & 2341 & \\
\hline jun-jul-ago- & 2251 & 2335 & 2357 & 2322 & 2281 & 2300 & 2355 & 2351 & \\
\hline jul-ago-set- & 2248 & 2335 & 2365 & 2320 & 2277 & 2312 & 2346 & 2349 & \\
\hline out-nov-dez- & 2240 & 2316 & 2361 & 2282 & 2297 & 2327 & 2363 & 2371 & \\
\hline
\end{tabular}

Fonte: IBGE, Pesquisa Nacional por Amostra de Domicílios Contínua

Nota: Somente os dados hachurados são comparáveis.

- A análise do rendimento médio real habitualmente recebido no trabalho principal, segundo os grupamentos de atividade, do trimestre móvel de janeiro a março de 2020, em relação ao trimestre de outubro a dezembro de 2019 , mostrou que todos os grupamentos apresentaram estabilidade. A comparação com o trimestre de janeiro a março de 2019 mostrou que não houve crescimento em qualquer categoria. Houve redução no grupamento de Serviços domésticos (2,5\%, ou menos $R \$ 24)$.

- A análise do rendimento médio real habitualmente recebido no trabalho principal, segundo a posição na ocupação, do trimestre móvel de janeiro a março de 2020, em relação ao trimestre de outubro a dezembro de 2019, mostrou aumento na categoria Empregado no setor privado (exclusive trabalhador doméstico) de $2,8 \%$, ou mais $R \$ 56$. As demais categorias não apresentaram variação. A comparação com o trimestre de janeiro a março de 2019 indicou que não houve crescimento em qualquer categoria. 


\section{MASSA DE RENDIMENTO REAL}

- A massa de rendimento real habitualmente recebido em todos os trabalhos pelas pessoas ocupadas foi estimada, para o trimestre móvel de janeiro a março de 2020, em $\mathrm{R} \$ 216,3$ bilhões de reais, e quando comparada ao trimestre móvel de outubro a dezembro de 2019 apresentou variação de $-1,3 \%$, ou seja, menos R\$ 2,9 bilhões. Frente ao mesmo trimestre do ano anterior, houve estabilidade na massa de rendimentos.

Nos gráficos, a seguir, são apresentadas as informações referentes aos trimestres passíveis de comparação.

Gráfico 1 - Taxa de desocupação das pessoas de 14 anos ou mais de idade, na semana de referência, de todos os trimestres comparáveis - Brasil - 2012/2020 (em \%)

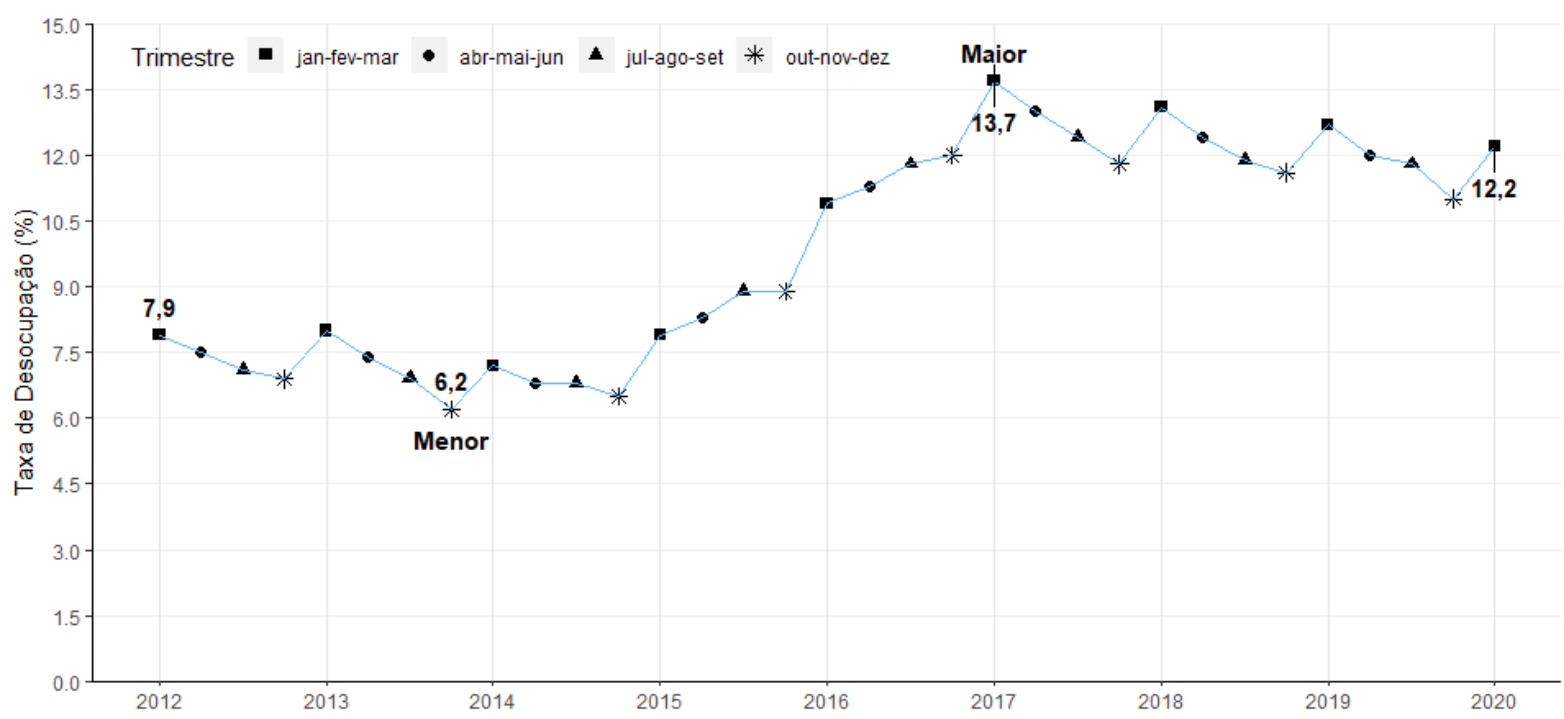

Fonte: IBGE, Diretoria de Pesquisas, Coordenação de Trabalho e Rendimento, Pesquisa Nacional por Amostra de Domicilios Contínua 
Gráfico 2 - Taxa de desocupação das pessoas de 14 anos ou mais de idade, na semana de referência dos trimestres de janeiro a março de 2020 - Brasil - 2012/2020 (em \%)

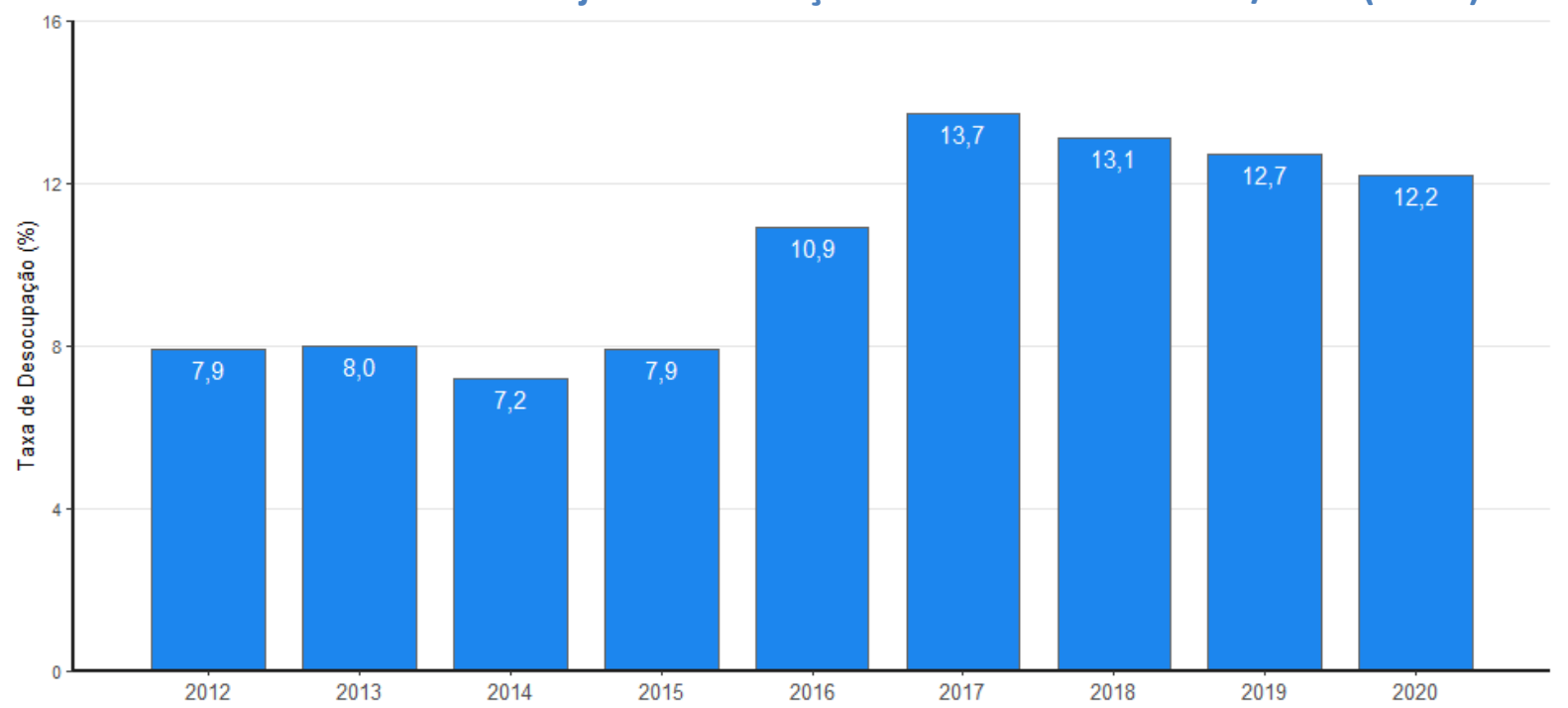

Fonte: IBGE, Diretoria de Pesquisas, Coordenação de Trabalho e Rendimento, Pesquisa Nacional por Amostra de Domicilios Contínua.

Gráfico 3 - Pessoas de 14 anos ou mais de idade, desocupadas na semana de referência Brasil - 2012/2020 (em mil pessoas)

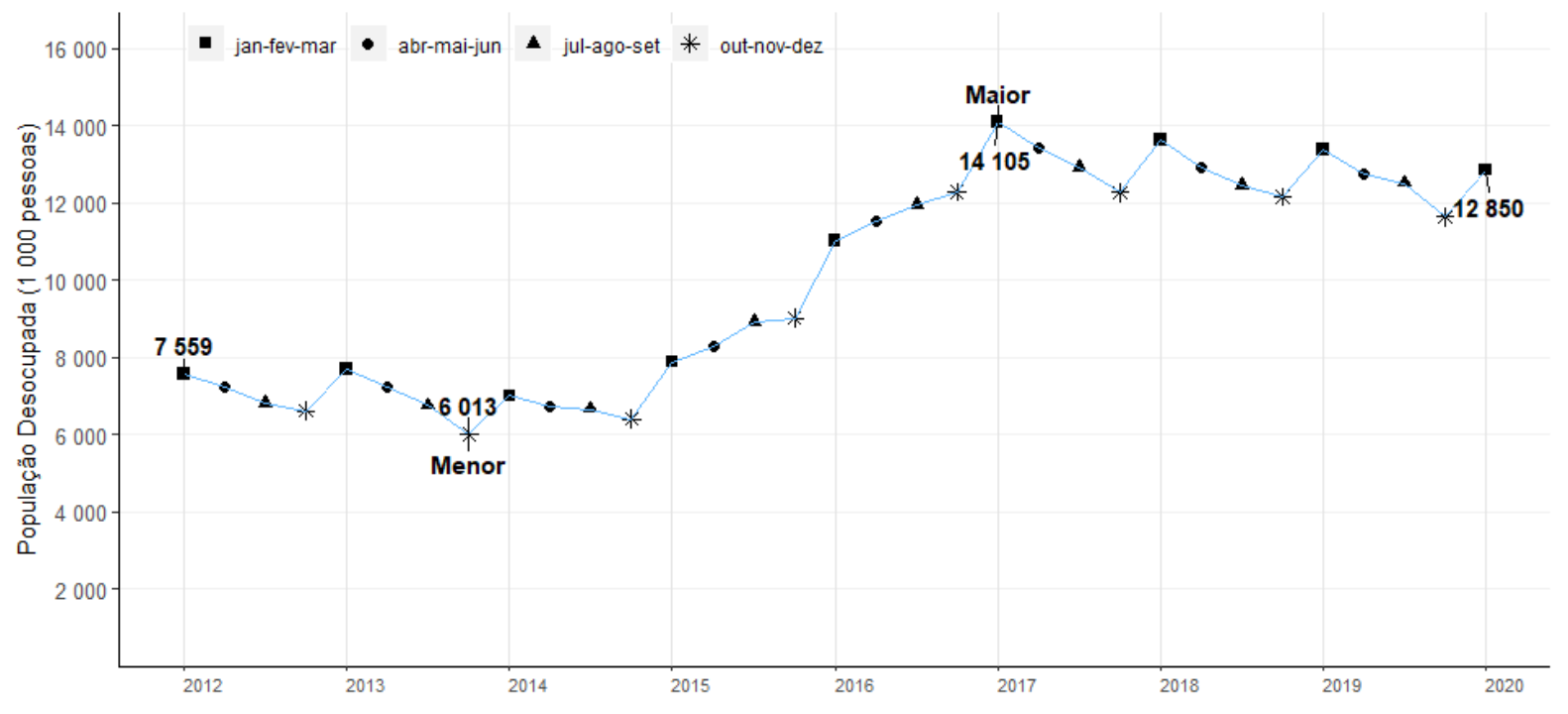

Fonte: IBGE, Diretoria de Pesquisas, Coordenação de Trabalho e Rendimento, Pesquisa Nacional por Amostra de Domicílios Contínua 
Gráfico 4 - Variação percentual das pessoas de 14 anos ou mais de idade, desocupadas na semana de referência em relação ao trimestre anterior - Brasil - 2012/2020 (em \%)

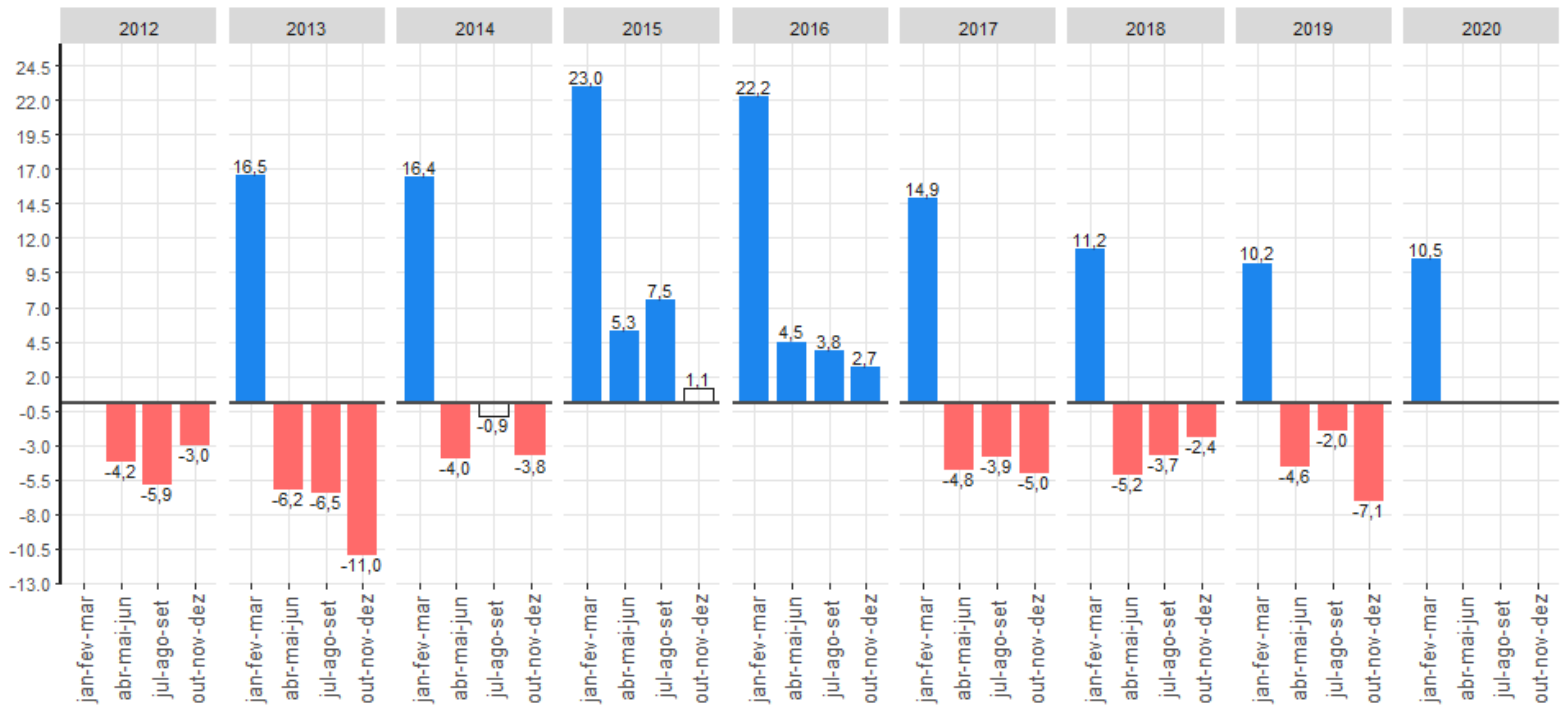

Fonte: IBGE, Diretoria de Pesquisas, Coordenação de Trabalho e Rendimento, Pesquisa Nacional por Amostra de Domicílios Contínua Nota: As colunas em branco com contorno cinza representam variações não estatísticamente significativas.

Gráfico 5 - Variação das pessoas de 14 anos ou mais de idade, desocupadas na semana de referência, em relação ao mesmo trimestre móvel do ano anterior - Brasil - 2012/2020 (em $\%)$

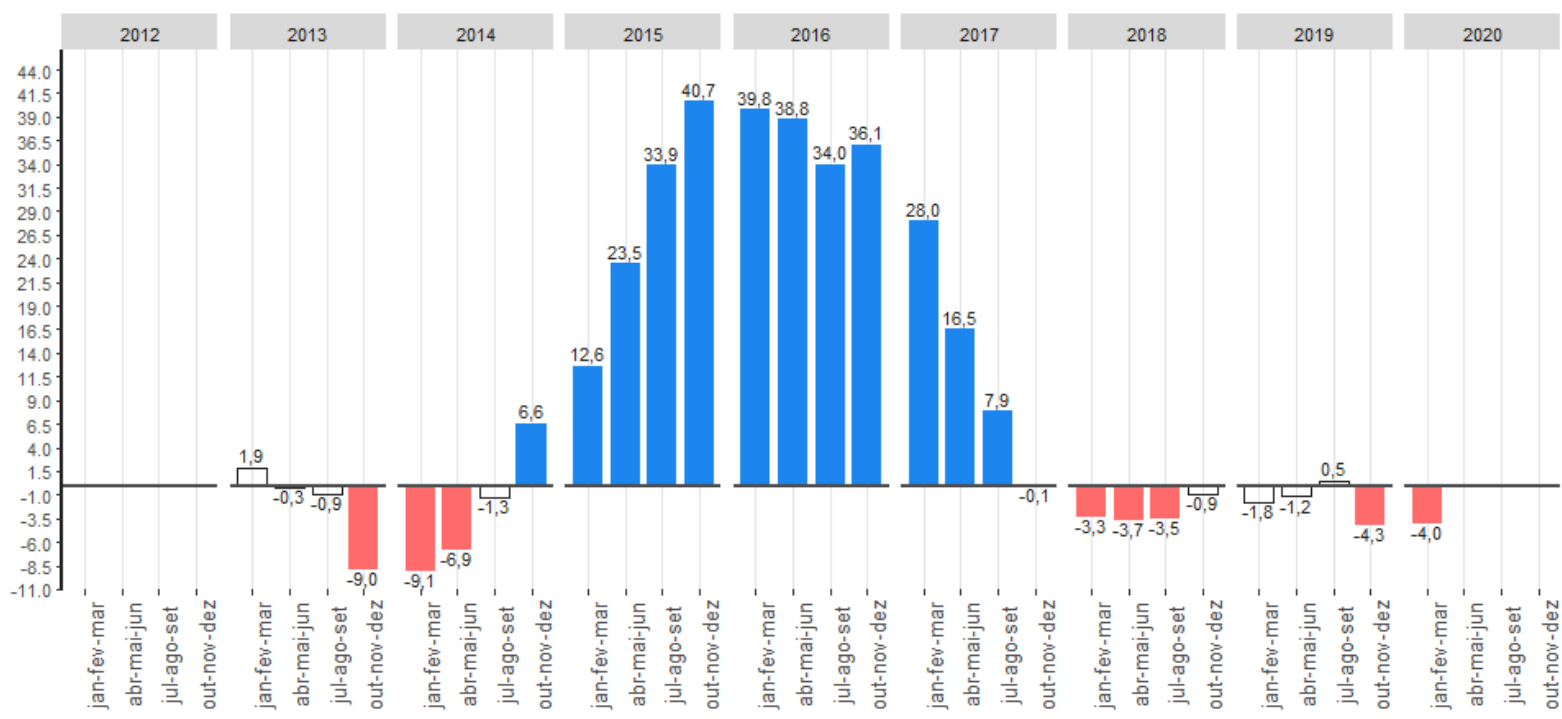

Fonte: IBGE, Diretoria de Pesquisas, Coordenação de Trabalho e Rendimento, Pesquisa Nacional por Amostra de Domicílios Contínua. Nota: As colunas em branco com contorno cinza representam variações não estatísticamente significativas. 
Gráfico 6 - Pessoas de 14 anos ou mais de idade, ocupadas na semana de referência - Brasil - 2012/2020 (em mil pessoas)

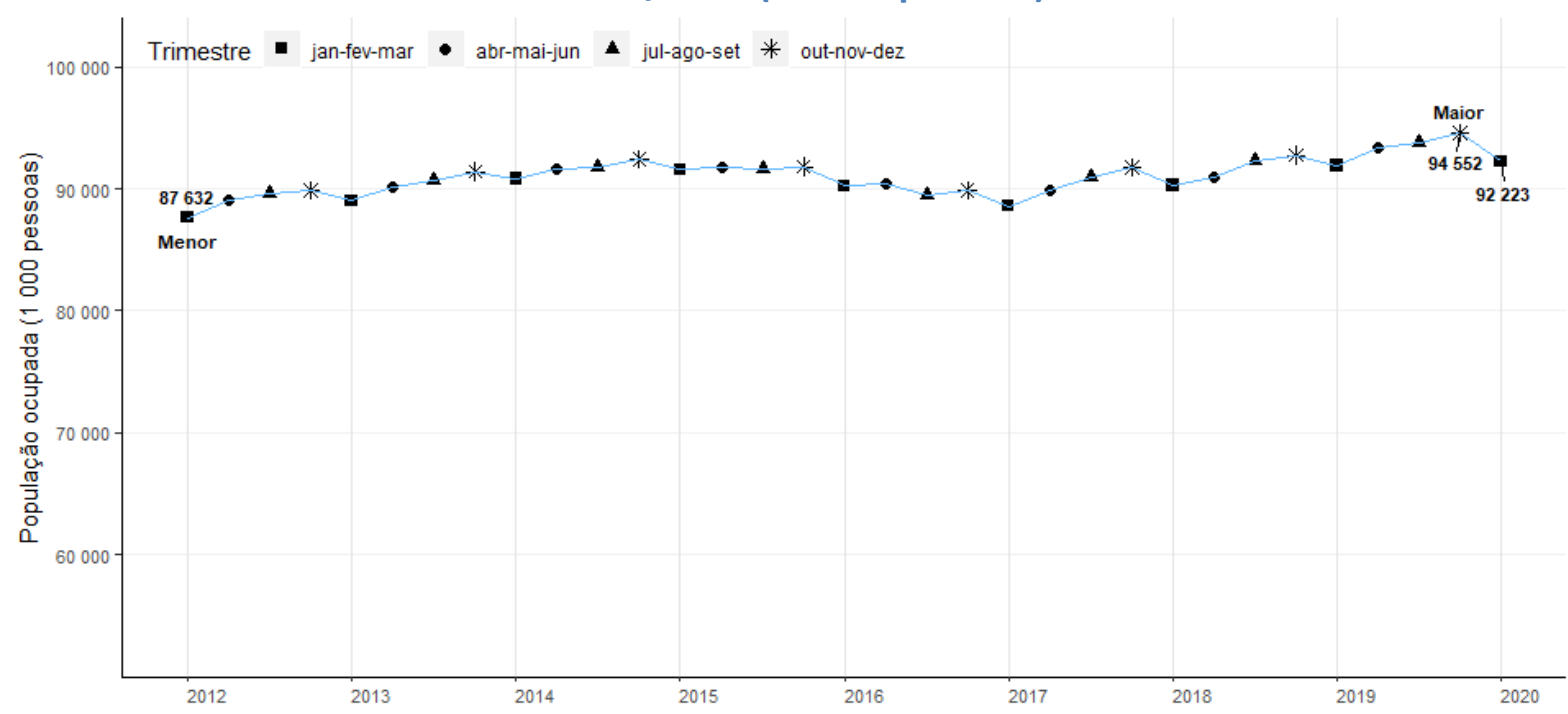

Fonte: IBGE, Diretoria de Pesquisas, Coordenação de Trabalho e Rendimento, Pesquisa Nacional por Amostra de Domicílios Contínua

Gráfico 7- Nível da ocupação das pessoas de 14 anos ou mais de idade, na semana de referência - Brasil - 2012/2020 (em \%)

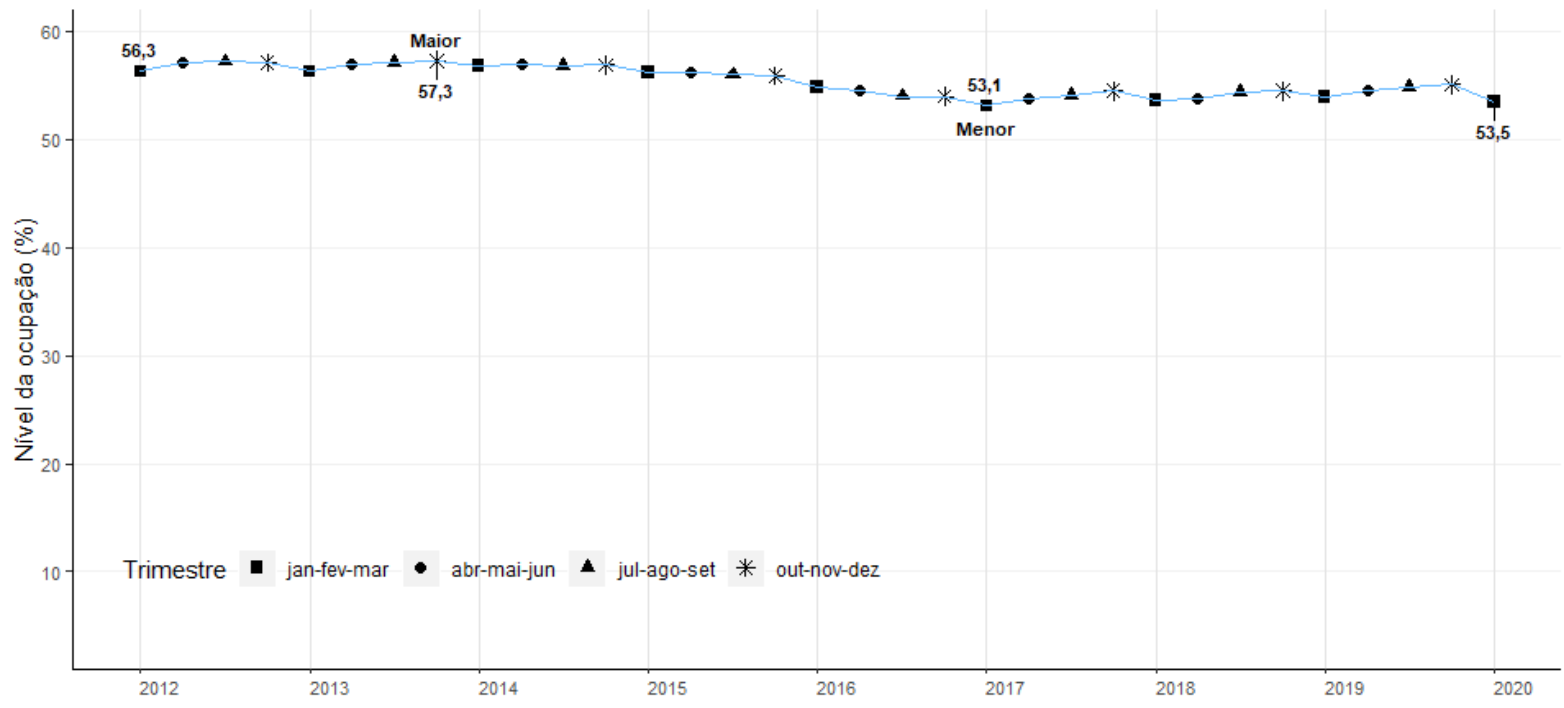

Fonte: IBGE, Diretoria de Pesquisas, Coordenação de Trabalho e Rendimento, Pesquisa Nacional por Amostra de Domicilios Contínua 
Gráfico 8 - Variação das pessoas de 14 anos ou mais de idade, ocupadas na semana de referência em relação ao trimestre anterior - Brasil - 2012/2020 (em \%)

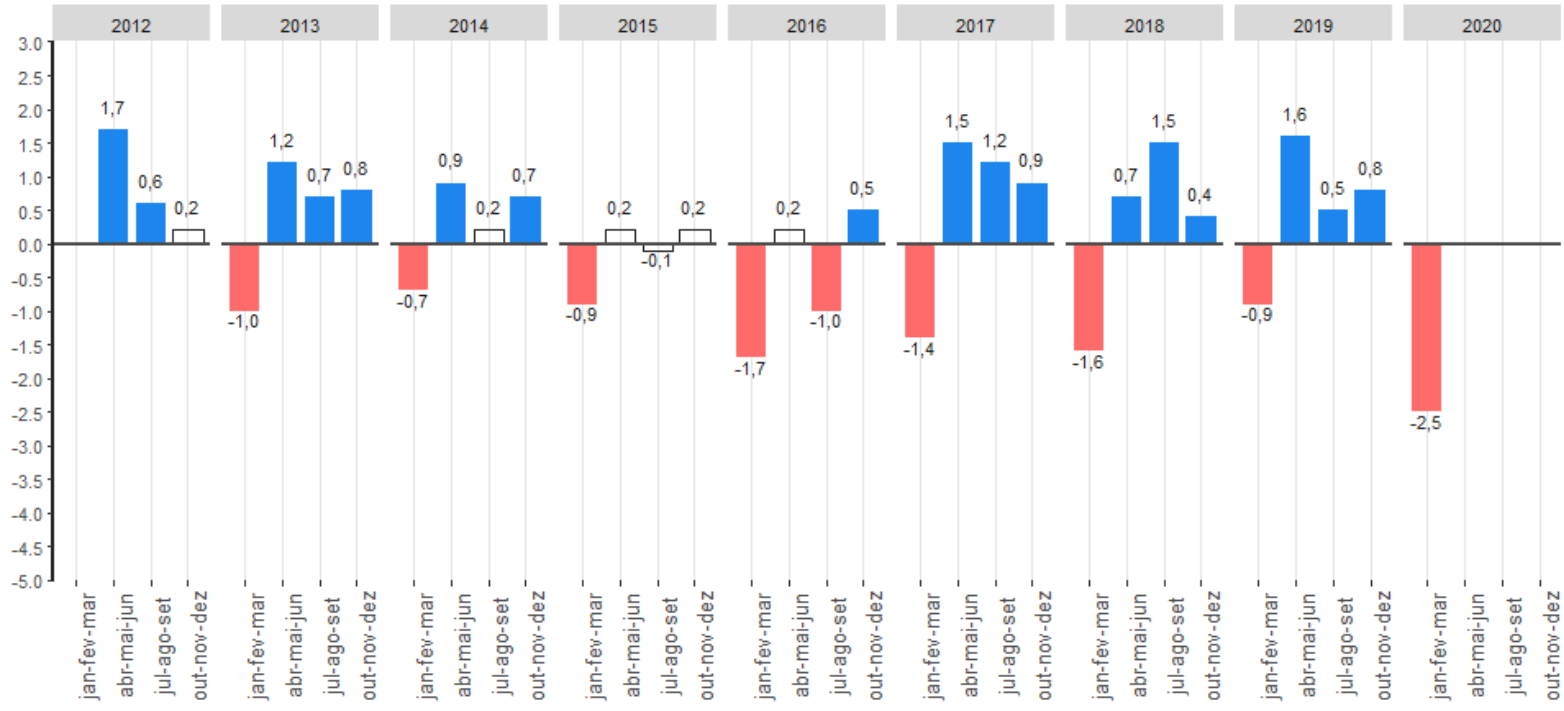

Fonte: IBGE, Diretoria de Pesquisas, Coordenação de Trabalho e Rendimento, Pesquisa Nacional por Amostra de Domicílios Contínua Nota: As colunas em branco com contorno cinza representam variações não estatísticamente significativas.

Gráfico 9 - Variação das pessoas de 14 anos ou mais de idade, ocupadas na semana de referência em relação ao trimestre do ano anterior - Brasil - 2012/2020 (em \%)

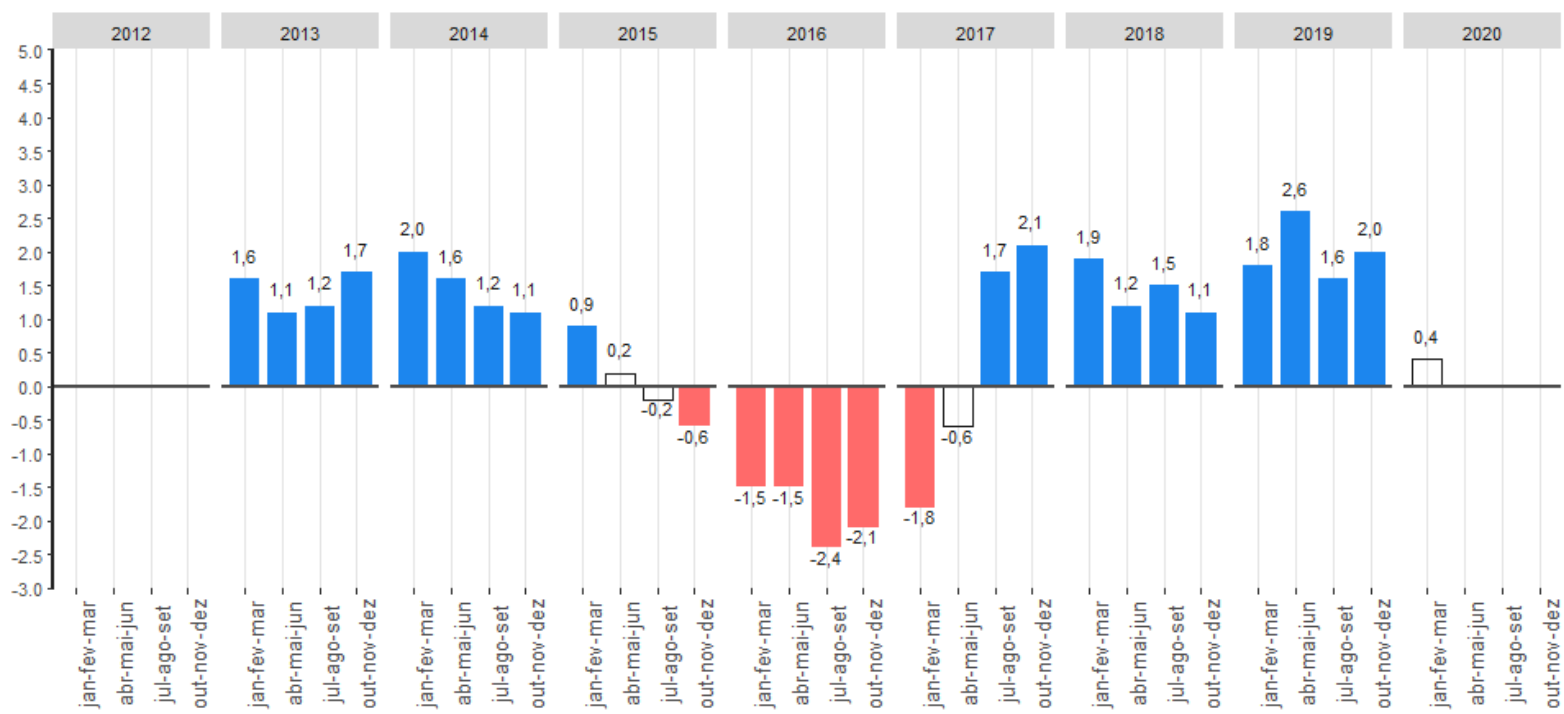

Fonte: IBGE, Diretoria de Pesquisas, Coordenação de Trabalho e Rendimento, Pesquisa Nacional por Amostra de Domicilios Contínua Nota: As colunas em branco com contorno cinza representam variações não estatísticamente significativas. 
Gráfico 10 - Taxa de Composta de subutilização da força de trabalho nos trimestres de janeiro a março - Brasil - (em \%) - 2012/2020

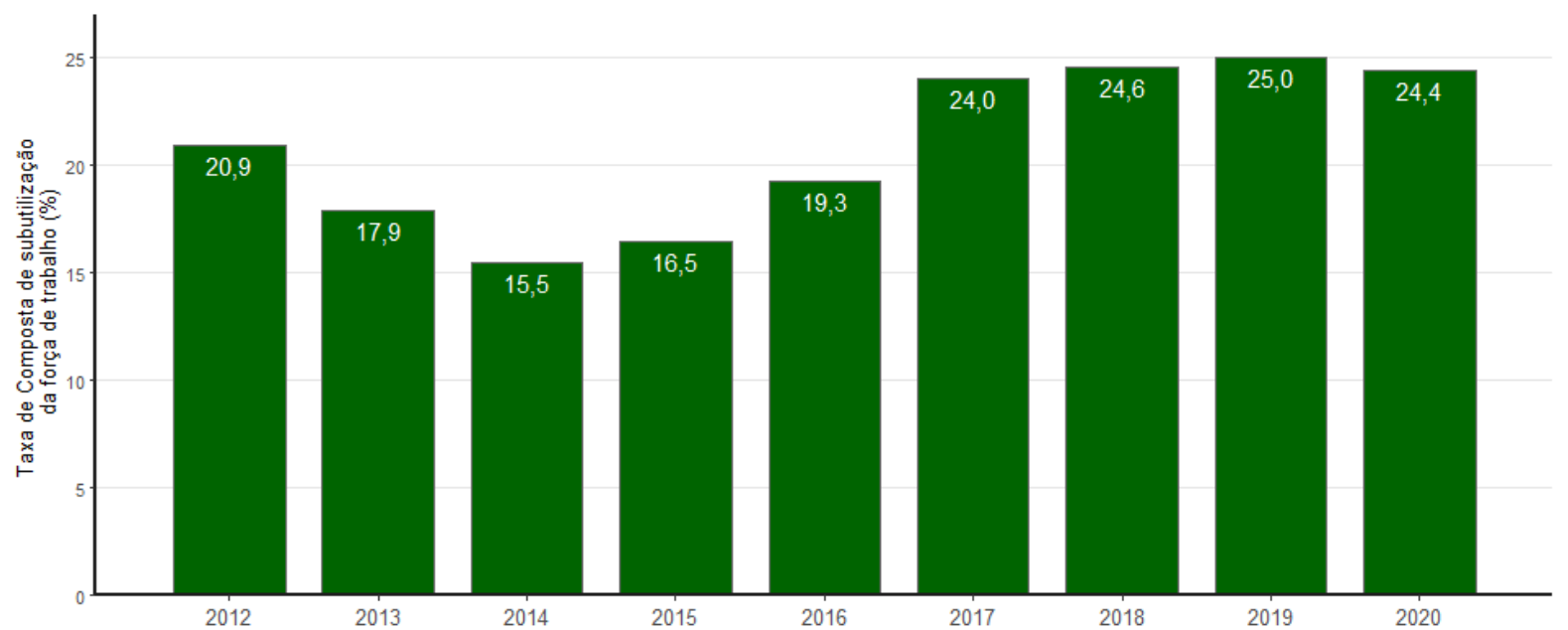

Fonte: IBGE Diretoria de Pesquisas, Coordenação de Trabalho e Rendimento, Pesquisa Nacional por Amostra de Domicilios Contínua

Nota: A partir do $4^{\circ}$ trimestre de 2015 houve mudança de conceito na subutilização da força de trabalho por insuficiência de horas trabalhadas.

Anteriormente, considerava-se no cálculo do indicador as horas efetivamente trabalhadas e, a partir do referido trimestre, as habitualmente trabalhadas. Houve ainda mudança na forma de captação do quesito de horas trabalhadas.

Gráfico 11 - Percentual de pessoas desalentadas na população na força de trabalho ou desalentada - Brasil - 2012/2020 (em \%)

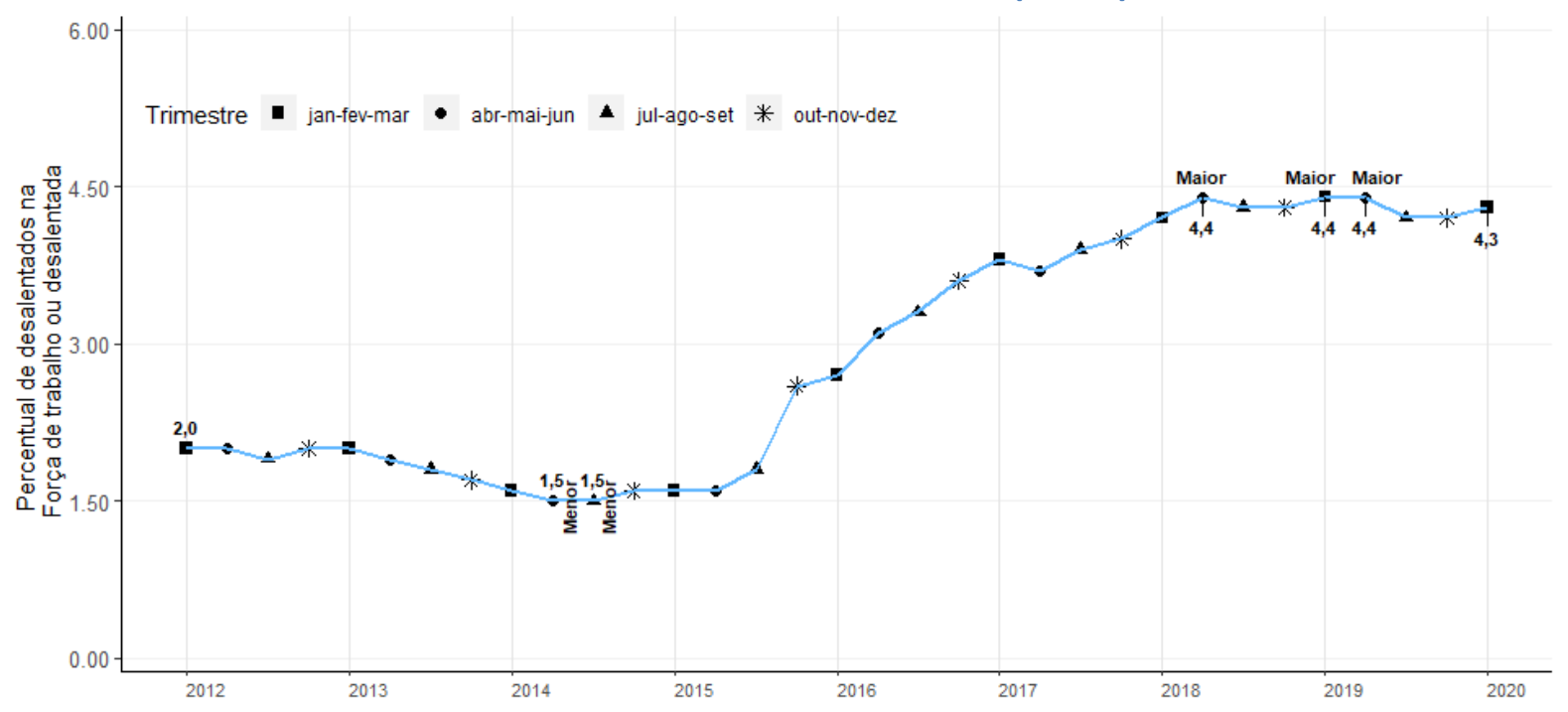

Fonte: IBGE, Diretoria de Pesquisas, Coordenação de Trabalho e Rendimento, Pesquisa Nacional por Amostra de Domicílios Contínua. 
Gráfico 12 - Rendimento médio real de todos os trabalhos, habitualmente recebido por mês, pelas pessoas de 14 anos ou mais de idade, ocupadas na semana de referência, com rendimento de trabalho - Brasil - 2012/2020 (em reais)

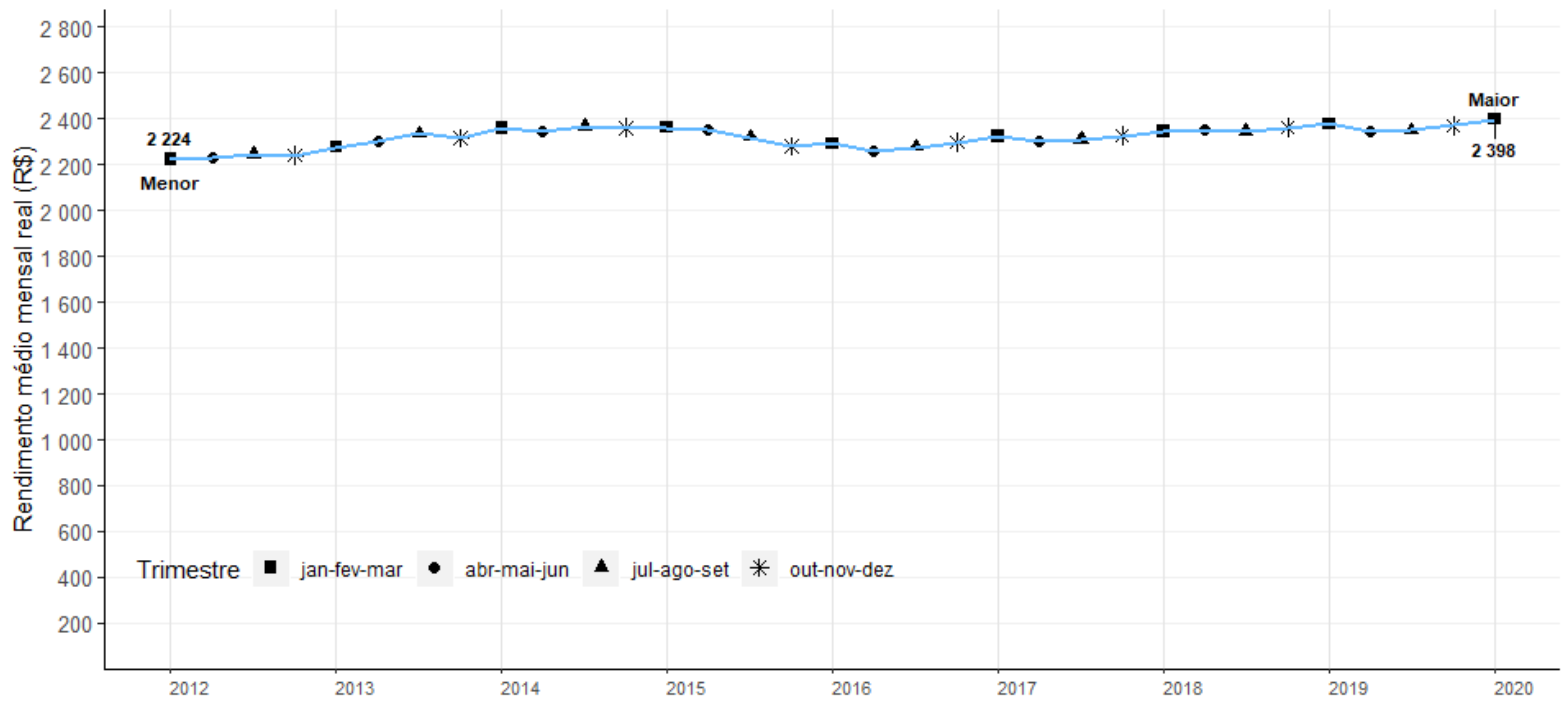

Fonte: IBGE, Diretoria de Pesquisas, Coordenação de Trabalho e Rendimento, Pesquisa Nacional por Amostra de Domicílios Contínua

Gráfico 13 - Variação do rendimento médio real de todos os trabalhos, habitualmente recebido por mês, pelas pessoas de 14 anos ou mais de idade, ocupadas na semana de referência, com rendimento de trabalho, em relação ao trimestre móvel anterior - Brasil 2012/2020 (em \%)

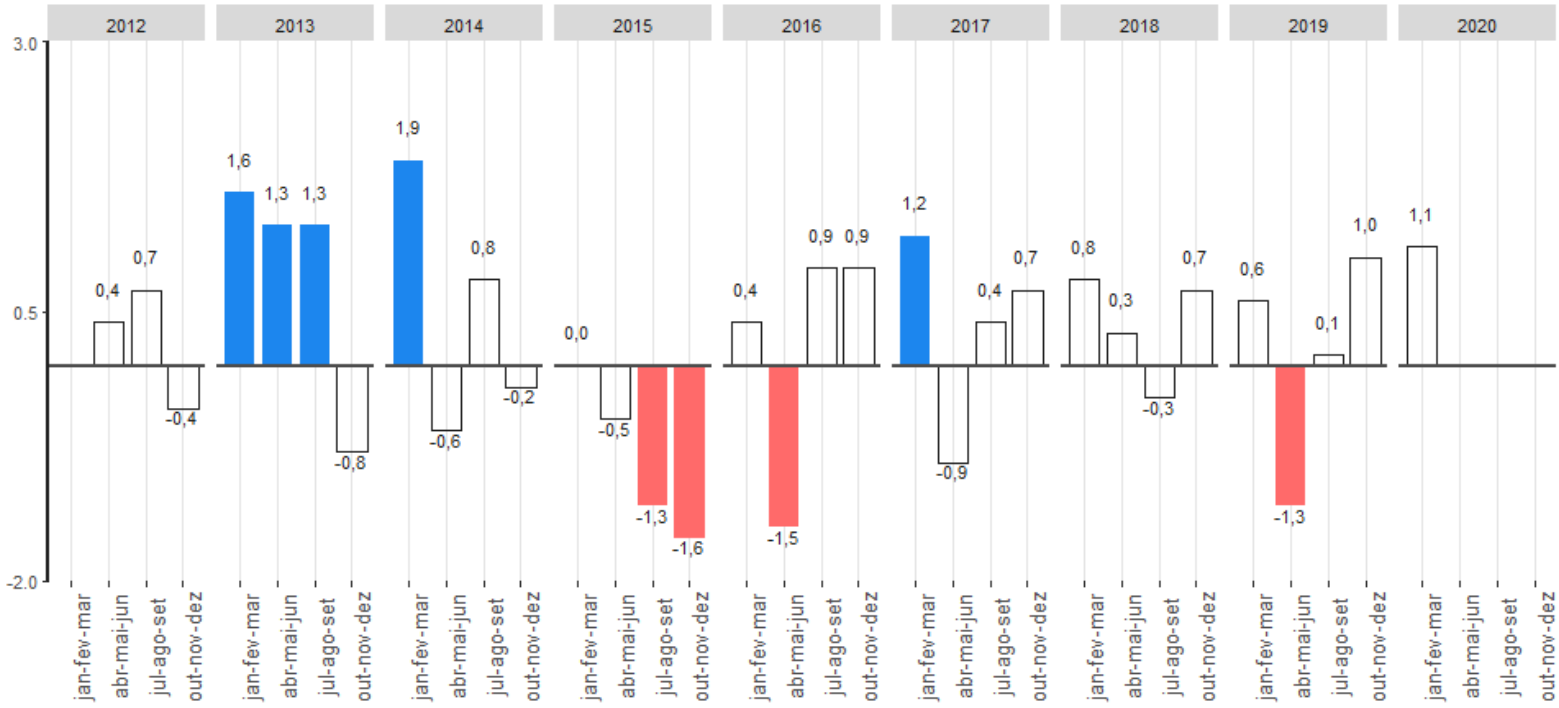

Fonte: IBGE, Diretoria de Pesquisas, Coordenação de Trabalho e Rendimento, Pesquisa Nacional por Amostra de Domicilios Contínua. Nota: As colunas em branco com contorno cinza representam variações não estatísticamente significativas. 
Gráfico 14 - Variação do rendimento médio real de todos os trabalhos, habitualmente recebido por mês, pelas pessoas de 14 anos ou mais de idade, ocupadas na semana de referência, com rendimento de trabalho, em relação ao mesmo trimestre móvel do ano anterior - Brasil - 2012/2020 (em \%)

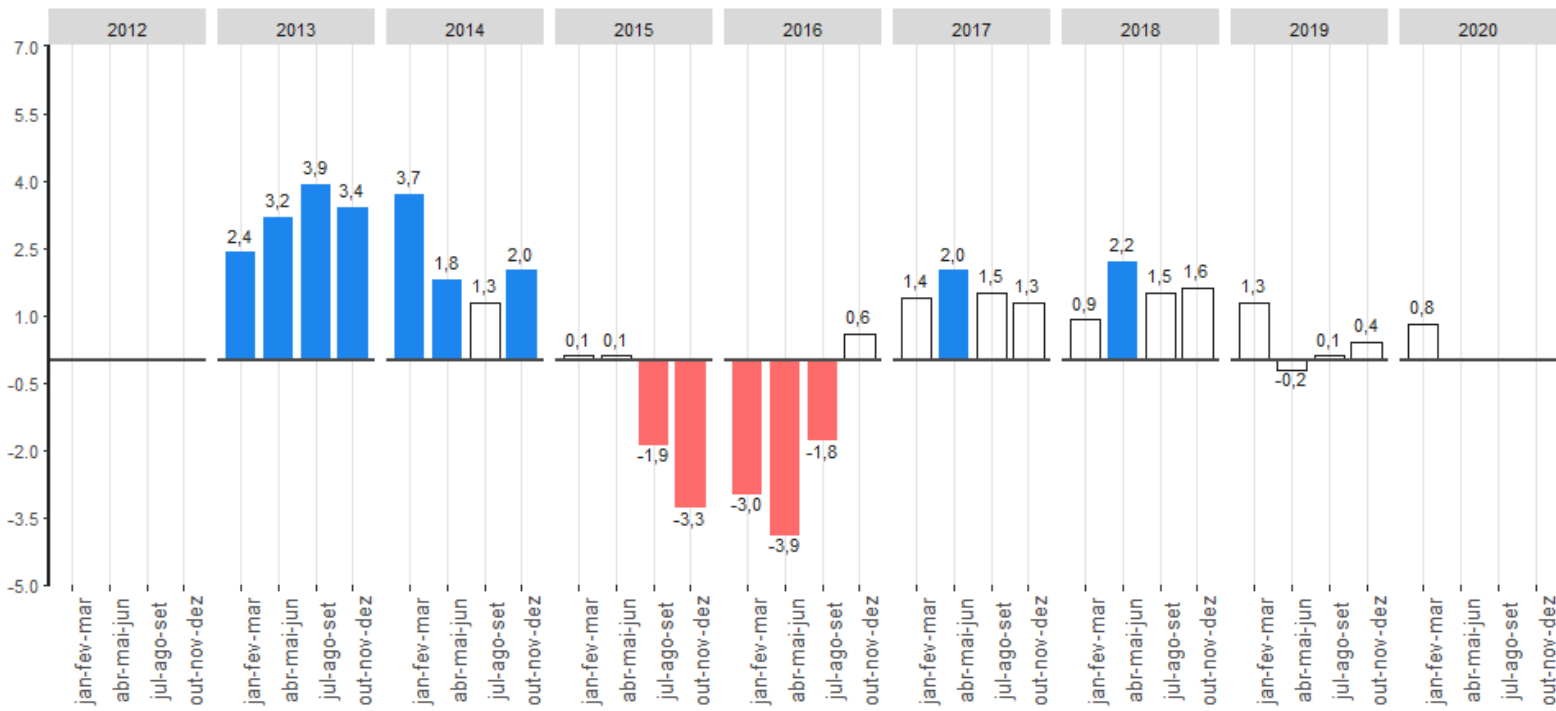

Fonte: IBGE, Diretoria de Pesquisas, Coordenação de Trabalho e Rendimento, Pesquisa Nacional por Amostra de Domicilios Contínua Nota: As colunas em branco com contorno cinza representam variações não estatísticamente significativas.

Gráfico 15 - Massa de rendimento real de todos os trabalhos, habitualmente recebido por mês, pelas pessoas de 14 anos ou mais de idade, ocupadas na semana de referência, com rendimento de trabalho - Brasil - 2012/2020 (em milhões de reais)

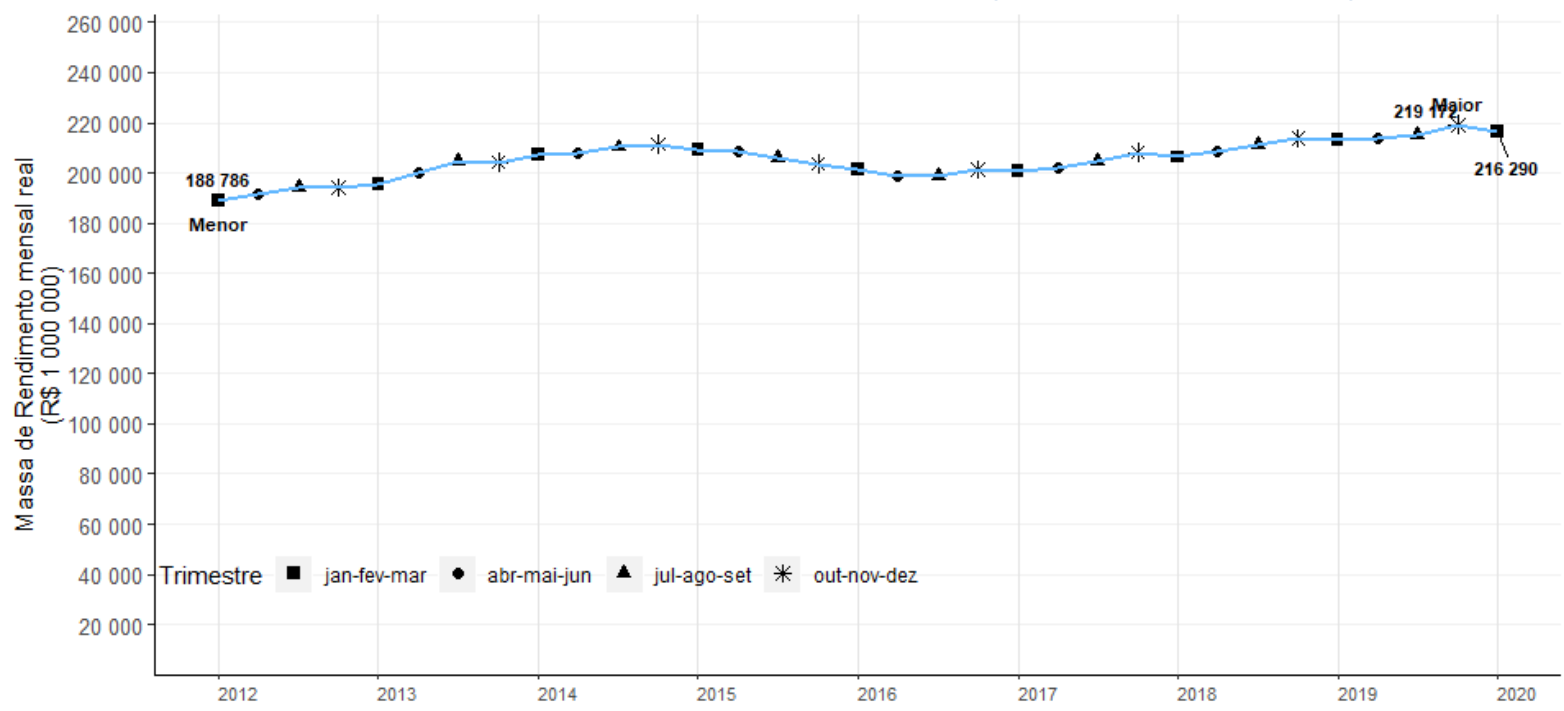

Fonte: IBGE, Diretoria de Pesquisas, Coordenação de Trabalho e Rendimento, Pesquisa Nacional por Amostra de Domicílios Contínua. 
Gráfico 16 - Pessoas de 14 anos ou mais de idade, fora da força de trabalho na semana de referência - Brasil - 2012/2020 (em mil pessoas)

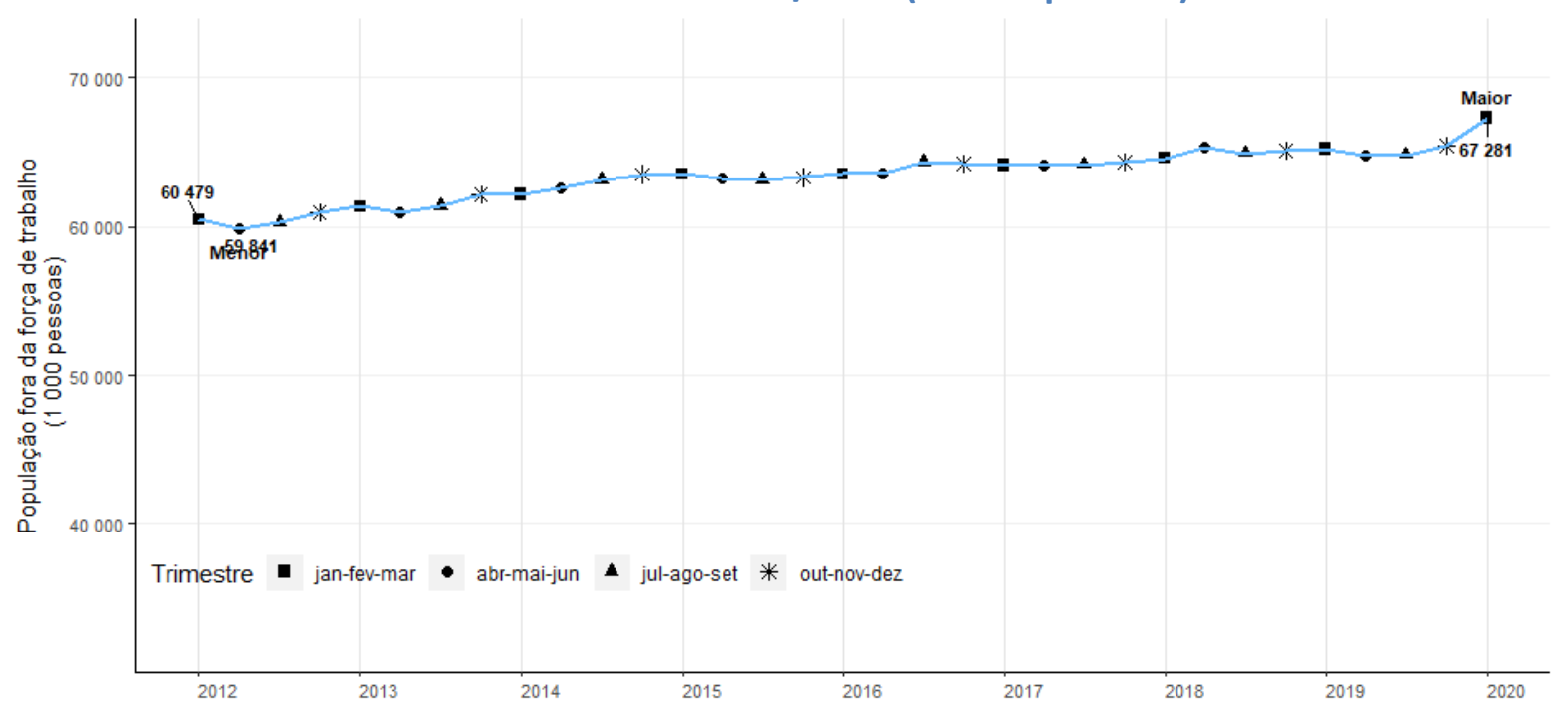

Fonte: IBGE, Diretoria de Pesquisas, Coordenação de Trabalho e Rendimento, Pesquisa Nacional por Amostra de Domicílios Contínua.

Rio de Janeiro, 30 de abril de 2020. 